\title{
Analysis of the B2C Mode of Mbaobao and Strategies for Vertical E-commerce
}

\author{
Shijie Jiang, Chen Zhang, Bin Huang \\ School of Media Studies \& Humanities \\ Zhejiang University City College \\ Hangzhou, 310015, China \\ E-mail:18768104284@163.com
}

\begin{abstract}
Facing the tremendous temptation of the Internet, a large amount of the traditional industry enterprises have rushed to start with the E-commerce. Mbaobao is a successful example of E-commerce. It has developed rapidly in the B2C E-commerce, and has become the largest Brand Sales of bags on the Internet. The main reason is an innovative B2C mode of Mbaobao takes "fast" as center of the vertical online sales and has private multi-brand. This article intends to have an in-depth discussion of Mbaobao in several areas.The profit mode, revelation and significance. We propose appropriate strategic actions and address current issues.
\end{abstract}

Keywords- the B2C mode of Mbaobao, core competitiveness, vertical e-commerce, the significance of Mbaobao

\section{INTRODUCTION}

In the conversion of OEM (original equipment manufacturer) into the brand enterprise, Mbaobao experienced failure in the combination of online and offline operations. And it has changed its business mind and shift from the "heavy" entity to the "light" online. Strategically, it settled in Taobao which share 80 percent of online purchase in China, and Mbaobao quickly become a famous Taobao brand. Then Mbaobao developed its brands and independent B2C platform through Taobao, as borrowing ship to launch out. Moreover, Mbaobao is stepping up into international market, and there is a website in Japan and North America market.

The sales of Mbaobao have continued to grow nearly 10 times per year, 3.8 million RMB in 2008, 4 million RMB in 2009, 40 million RMB in 2010, nearly 5 million $\mathrm{RMB}$ in 2011. Mbaobao which whole sales exceed 10 million RMB has become the first online B2C Company by its multi-brand and hierarchical marketing in a short period of three years.

\section{The Profit Mode Analysis Of Mbaobao}

------ The self owned multi-brand takes "fast" as center of the vertical online sales.

\section{A. The new fast fashion mode}

The new fast fashion mode of Mbaobao: 15 days from finding the new popular elements to small-batch presales. A series of 30 new bags will be launched every Tuesday, The average stock cycle is 45 days (the fastest conversion process of the fashion clothes is 6 weeks). The objective of
Mbaobao is to give customers quality fashion bags for a fraction of the price. The brand name of Mbaobao is the embodiment of customer satisfaction.

\section{B. The whole integrated online marketing}

"Where the customers are, where the bags we sale" This is the marketing policy that Mbaobao has carried out .The advantages of the Internet are well known and utilized by Mbaobao. Mbaobao has expanded marketing to be available World-wide.

- $\quad$ According to the latest data by iResearch, Taobao ranked first in size of market trading in 2012 Q3 China C2C online shopping website, accounting for 94.43\%. Seen from the B2C market, Tmall also ranked first with 54.6\%.Though Mbaobao was independent from Taobao, as a related shop it can still be searched out more than 1700 on Taobao. Taobao, an online shopping mall attracts a plenty of consumers

- Mbaobao has cooperation with many online shopping malls: To name a few 360buy, M18, Dangdang, 1mall, and Sunning. This enhances brand awareness reaching potential customers.

- Propagandizing in many online marketing platforms: To name a few MAIYATANG Emagazine, MAIYATANG.COM, official blog, micro blog, and Tianya to spread its brand mind in forms of text and graphics. After the new revision, Mbaobao's official website is now add two channels:" shopping" that gathering the rules of fashionable collocation, " show your bags" is a waterfall forms of interactive community.

- Mbaobao customizes an email direct marketing planning of memberships to improve the efficiency of market experience feedback before the new listing. The effect is very obvious. Take the weekly products example, the transformation rate of the order maintains around $40 \%$ to $45 \%$.

- "Mobile Mbaobao " including mobile portal and mobile APP - the Mbaobao's iPhone, Android and Wap client. This is the only one mobile Ecommerce application, which is specialized vertical luggage industry and used in domestic market.

In addition to online marketing, Mbaobao also carried out TVC advertising sales and event marketing. For example, organizing the first bags brand show in 
China International Fashion Week ---- "Mbaobao JAMIEMOORE 2012spring and summer new products conference"

\section{Quick response of the supply chain system $(Q R)$}

Mbaobao combines Wal-Mart's QR mode with its own characteristics. And creates its M2C (Manufacturers to Consumer) mode based on network Through the network order-driven, this mode automatically synchronizes to the hand-held terminal in every link of supply chain . So far, the current monthly average inventory accounts is less than $1 \%$, and the inventory cycle shortens from 12 weeks to 6 weeks. Less than 10 minutes that a product from putting on web pages to being ordered by the customer.

\section{The private brand multi-brand\& intermediary brand}

MBaoBao has set up scores of private brands, such as "feel'young” ,"LoveMatch” ,"KATANG”, to satisfy various people. At the same time, just like what Haifeng Ye said, "At the beginning of the business, Mbaobao was just an online agency. But independent B2C mall does not only to sale its own products." Obviously, famous brands open up the sales channels for Mbaobao. However, a big problem arose that the channel agency is hard to price at a premium. Then it stimulates the transformation of Mbaobao, its self-owned 15 brands have reached more than $75 \%$ sales.

\section{E. The vertical e-commerce enterprise of bags industry}

As a leading enterprise of vertical e-commerce, Mbaobao has been developing for five years, and focuses on bags all the time. And become a domestic fashion bags website with most types of bags by dividing products line through age, category, region and style, to met consumer needs of different goals and levels.

\section{REVELATION \& SigNIFICANCE}

\section{A. For different kind of E-commerce enterprises}

For the transition of OEM: Change thinking mode, and concentrate on the exploration and establishment of Ecommerce mode. Customers determine what enterprise to produce. And on the other hand, online marketing channel is not only a supplement to the traditional one, but subversion.

For Enterprise which newly try E-commerce: Self-built platform or settled- in platform? That is a question. Traditional enterprises which newly try E-commerce have 3 situations. The 1st one is of small size, positioning new channel; the 2nd one is of middle size, positioning new business; the last one is of large scale, positioning a new pattern. All are related to funds, costs and ROI. it is applicable for the 1st one to settle in platform; the 2nd one choose multiple ways involve self-built platform, settled-in platform and authorized network distribution. The last one chooses completely self-built platform. However, no matter which way to choose, station E-commerce means combination off-line with online. Making a choice or keeping the balance between them is the key point. Meanwhile, enterprise could run further if it keeps" returnto-zero" attitude along.

For enterprise of trial and error: The example of MBaoBao informs numerous enterprises: E-commerce allows trial and error. And enterprise could find out the appropriate commercial thinking and brand strategy through trial and error step by step.

For Vertical E-commerce enterprises: Specialization is the core. Running a vertical E-commerce enterprise requires a persistent "intense cultivation" in one field or segment market. And also persist in the view that the more vertical a brand is, the more valuable it is. Do not covet others with big market size.

For Diverse e-commerce enterprises: Although Mbaobao follows vertical E-commerce route, B2C mode is common shared, and this is a significant feature of the Internet.

\section{B. E-commerce mode innovation: Accurate positioning and core competitiveness}

The biggest feature of the Internet is fast spread and easy to copy. Once a business mode is regarded as success, numerous followers will imitate.

E-commerce mode needs innovation and Mbaobao is an innovator. Its "fast fashion" new mode is the microinnovation to Zara, M2C also innovate Wal-Mart' QR The fact proves that innovation in E-commerce mode will provide a development opportunity for traditional massive economic, and play an important role in integrating industry chain and promoting upgrading of traditional industries.

However, if enterprise does not have its own positioning and core competitiveness, it will be in "Red Ocean”. On one hand, innovation makes no point, On the other hand, the enterprise which was imitated will be easy to exceed. Like rapid developed Redbaby, positioning mother and baby products at first, but now it is a dangerous signal that it expands to cosmetic, food and even digital products.

\section{Take "Fast" as the center}

"Fast" has been the core competitiveness of Mbaobao. Fast fashion, integrated marketing and QR just correspond to 3 aspects: product, marketing, supply chain.

- The CEO of Mbaobbao Haifeng Ye said that product is our company's soul. Products, especially fashion consumer goods. When enterprise guarantees the quality, product innovation and its efficiency is the key for its success or failure. For instance, Clothing occupying the largest market shares in 2011 China B2C market, with online shopping times is coming and fast fashion is growing up, consumer require shorter promotional cycle, faster updating speed, and even different styles in the same updating speed. 
- The advantages of the Internet Marketing are low cost, wide audience and fast speed. With the Internet popularized, the number of China Netizen is 0.538 billion, and online shoppers is nearly 0.2 billion in2012. These provide a huge market for Emarketing, and then promote development of Ecommerce. Take online advertising as example, The latest data by iResearch from “2011-2012 Internet Advertising Survey Respondents’ Behavior Research" shows that the Netizen's attitude to online advertising is friendly and take it as vital tool when decision making.

- $\quad$ The whole network marketing is not only a variety of marketing, but also an effective integration; more like" Indeed affect the whole body". So beginnings with "Single-point breakthrough", like Mbaobao make use of its Taobao brand. Then other online promotion measures make a synergistic effect.

- $\quad$ Supply Chain Management is enterprise’s validity management, shows optimization of workflow and efficiency. QR focuses on quick response to consumer. The advantage of Innovative M2C is reducing circulation links to one-to-one and cost of sales. For consumer, get quality fashion bags for a fraction of the price and fast speed. For enterprise itself, get both public praise and low cost. Thus reach a win-win situation.

In summary, like Mbaoabao's QR supports its” Fast fashion" and the whole network integrate marketing. Only when product, marketing and supply chain are complementary can enterprise establish its competitiveness.

\section{Brand}

"I think the core of enterprise development is brand. We are living in material accumulation times. You do anything all may have forerunner. Whatever we do is to build brand in final and the more vertical a brand is, the more valuable it is in fact. That is our route."

- The CEO of MBaoBbao: Haifeng Ye

Channel agency values the effect of famous brands: public praise, large flow, low cost in trial and error .Selfowned brand, although tough, the advantage is obvious: low pricing, independent controlling cost. Also has its own special attribute to reduce similarity competition and promote consumer 'adhesion adhesion degree to the brand.

Brand strategy Management can be divided into 3types: multi-brand strategy like P\&G, brand extension, brand verticality like Mbaobao. However, in connection with developments for enterprise, the other two ways may well be a good option.

\section{The Issues And SugGestion}

Mbaobao is in rapid development now, sales amount increase in 10 times, at the same time, there still have some unsolved issues yet.

\section{A. With famous enterprise brand, propaganda for product brand is not enough.}

Mbaobao has 40 brands, however propaganda work always centers on enterprise brand--Mbaobao. Consumers know Mbaobao and heard "Buy bags,buy Mbaobao", but they may even do not know or remember "feel'young" "LoveMatch" KATANG" at all. So they do not have true brand loyalty in a sense, the only reason why they buy is fashion style, reasonable price or high Price/performance ratio.

There is response measure that propagandizing for both enterprise and product brand.

In propaganda, Mbaobao could learn P\&G's multibrand strategy-- strengthen product brand while weakening the enterprise brand. Mbaobao creates 15 brands, which is focusing on the effect of famous brand. Price is only one of the purchase demands; to enterprise, brand loyalty is the more expectable result.

Besides, online brand must consider marketing cost. Do not put into too much money to choose various marketing on various platforms. Appropriate marketing is the key and then make the product brand step by step.

\section{B. Only have Jiaxing and Guangzhou logistics centers that are not enough. And no self-built logistics}

Mbaobao' QR let stock orders handle time less than 10 minutes, but the speed of logistics that Mbaobao can not control which is an important index in consumer evaluation Like warehouse explosion and spring festival will influence logistics, besides the speed, consumer also have more requirements to delivery time and logistics service than before. With market size expanding, it is problem must be solved.

The suggestion is that Building more logistics centers, and even tries to equip self-built logistics delivery teams: This is what Mbaobao is doing now. Build Beijing Wuhan and Chengdu warehouses. There will be 5 centers in China. After Mbaobao has stronger strength and bigger market size, it can consider seeking self-built logistics as 360buy and Vancl to become a separate sub-warehouse and delivery operations service company of the E-commerce.

\section{CONCLUSION}

Buy bags? Buy Mbaobao. The success of B2C mode contributes to the success of Mbaobao. It results from the innovation by trail and error. The mode that takes "fast" as center of the vertical online sales and has private multibrand is being followed by a growing number of the ecommerce companies. However, Mbaobao who has strong competitiveness and accurate position is improving all the time and it is not afraid of being copied, because being modeled doesn't mean being surpassed..As a follower also need has own core core competitiveness and accurate position, thus you can innovate your own brand and mode.

The revelation and significance of Mbaobao's B2Cmode are useful for different kind of E-commerce enterprises, especially for the vertical E-commerce to learn 
and prictice. Even Mbaobao is facing some issues now, so it is necessary for followers to pay more attention to addressing current issues and proposing appropriate strategic actions .

\section{REFERENCES}

[1] N.Zhou, P.li Internet Marketing --The Bible to succeed in EBusiness: PUBLISHING HOUSE OF ELECTRONING INDUSTRY, Oct.2011

[2] "Mbaobao: "Fast marketing leads fast fashion in luggage industry" "http://www.cmmo.cn" Oct .2011

[3] K.Guo," logistics distribution bottleneck in the B2C mode" ,Modern Business, 430223

[4] W.J.Zhang, "Innovation based on E-commerce-- the B2B2C mode in Chinese clothes trade” QUNWENTIANDI,NO.12,2012,pp145146 